\title{
The development of an assessment system for dental vocational training and general professional training: a Scottish approach
}

\author{
L. E. Prescott, ${ }^{1}$ P. McKinlay, ${ }^{2}$ and J. S. Rennie, ${ }^{3}$
}

The role of competencies in postgraduate dental education and training has been a major topic of interest in recent years. Concerns have been voiced from all sides of the profession about how the competence of trainees and the quality of training can be assured so that high standards of patient care can be maintained. A three year project which seeks to develop a competency-based assessment system for general professional training is underway which hopes to answer some of the concerns and provide an evidence-based system of assessment for the early postgraduate years. This paper looks at the reasoning behind the project, its aims, and the progress made to date.

The introduction of mandatory Dental Vocational Training (DVT) on October 1st 1993 for all graduates wishing to hold an NHS list number within the General Dental Services (GDS) was a significant step for dentistry in the UK. The main objectives of DVT are to prepare dental graduates for independent practice through supervised education and training, and to promote high standards of patient care.

Although no formal structured evaluation of the outcomes of DVT has been undertaken, it is widely believed that a year's introduction to general dental practice, in a supervised and educationally supported environment has been a success. Recently, however, concerns have been raised about how well graduates are prepared for practice $^{1}$, about the role model provided by trainers ${ }^{1}$ and the lack of a formal system of assessment for the young graduate. ${ }^{2}$

While this debate is emerging in dentistry, summative assessment for vocational training in General Medical Practice became a

${ }^{1}$ Research Officer, Lister Postgraduate Institute, 11

Hill Square, Edinburgh.

${ }^{2}$ Training Manager, Lister Postgraduate Institute, 11 Hill Square, Edinburgh.

${ }^{3}$ Dental Director, SCPMDE, Hobart House, 80

Hanover Street, Edinburgh.

REFEREED PAPER

Received 02.03.00; Accepted 09.05.00

(C) British Dental Journal 2000; 190: 41-44 mandatory requirement in 1998 !

The debate about extending the training period for new graduates to two years has been alive almost since the first voluntary DVT schemes were launched around 20 years ago. ${ }^{3,4}$ In the White Paper 'Primary Care: Delivering the future ${ }^{5}$ a commitment was given to introducing two years of General Professional Training (GPT) for all new graduates.

Since then, a number of two-year schemes have been undertaken in different regions of the UK. GPT aims to build on the year spent training in general practice by giving trainees the opportunity to gain experience in the other branches of dentistry; namely the hospital and/or community services.

Although the two year schemes remain in pilot form at present, it is widely believed that by extending the supported and supervised environment for a second year and broadening the experience gained in both primary and secondary care, trainees develop a broad spectrum of transferable skills. It is anticipated that this will not only improve the standards of treatment and patient management but provide a solid foundation that enables trainees to make an informed career choice at the end of the training period. ${ }^{6}$ The two formal evaluations published fully support this view. ${ }^{7,8}$

\author{
In brief \\ - Objectives of postgraduate dental \\ training. \\ - DVT and GPT assessment. \\ - The project - progress.
}

\section{Objectives of postgraduate dental training}

The all-round capability of dental students upon graduation has been questioned in recent papers. ${ }^{9}$ The combination of an explosion of knowledge in dentistry and the increasing sophistication of therapeutic interventions has put increasing pressure on universities and students, and has lead to complaints that graduates are not as clinically competent as previously.

It is now widely accepted that the vocational training year is an essential period of transition from student to practitioner. A recent study revealed that 80 per cent of dental graduates believed that VT succeeded in preparing them for general practice. ${ }^{1}$ However, in the absence of a statutory and defined curriculum the training given is largely dependent on the particular experience, commitment and teaching ability of a trainer.

The award of an NHS list number to trainees who have completed VT suggests that a certain level of competence has to be achieved by a dentist before he/she can become a 'principal' in the GDS. The completion of VT at present rests upon the fulfillment of a contract signed at the beginning of the training period, which states that the VDP has undertaken one years full-time employment and has attended study courses totalling 30 days. Although the progress of the trainee is monitored in the Professional Development Portfolio there is no compulsory assessment system for VT and no defined standard which denotes the attainment of an acceptable level of competence. The lack of a competency framework for trainees has been of 


\section{EDUCATION competency}

major concern for trainers for some time. ${ }^{2}$

One method of assuring that the educational objectives of DVT and GPT are met would be through the introduction of a formal assessment process. To ensure that high standards of patient care are maintained, methods of assessing acceptable clinical competence must be identified. VDPs would be required to demonstrate that they have these competencies upon completion of their training.

A competency-based assessment system of this kind would also be a step towards guaranteeing the quality of training given to graduates. Trainee performance would be regularly monitored against competencybased outcomes, a process which would reveal difficulties or problems with the delivery of training at an early stage. Such issues could then be addressed and rectified.

\section{DVT and GPT assessment}

A three year project to develop an assessment system for DVT and GPT has been funded in Scotland. The aim of the project is to design a comprehensive, valid and reliable system of assessment that will embrace the continuum of undergraduate and early postgraduate dental education. Clinical training and assessment are integral to the BDS course and as the BDS serves as an entrance qualification to DVT / GPT it was considered essential to include the dental schools in this project. The project is overseen by a steering group which in addition to representatives from both dental schools in Scotland, includes VT advisers, dental tutors and trainers. The emphasis of the system being developed will be quality of assessment rather than quantity. Efficiency in determining the overall competence of the trainee will be one of the aims of the project.

The issue of assessment during DVT/ GPT has been addressed tentatively in recent months, ${ }^{10,11}$ and one of the major concerns about any new assessment system arises from the additional responsibilities which trainers would acquire. It is incorrect to think that such a system would be 'an enormous task, with wide implications. ${ }^{11}$ The objectives of DVT/GPT have not changed, nor the responsibilities of the

\begin{tabular}{|c|c|}
\hline Table I & lins and major competencies in dentistry \\
\hline Domain & Major competencies \\
\hline Clinical & $\begin{array}{l}\text { I Patient examination and diagnosis } \\
2 \text { Treatment planning and patient management } \\
3 \text { Heath promotion and disease prevention } \\
4 \text { Medical and dental emergencies } \\
5 \text { Anaesthesia, sedation, pain and anxiety control } \\
6 \text { Periodontal therapy and management of } \\
\text { soft tissue } \\
7 \text { Hard and soft tissue surgery } \\
8 \text { Non-surgical management of hard and soft } \\
\text { tissues of the head and neck } \\
\text { I0 Ranagement of the developing dentition } \\
\text { I I Replacement of teeth }\end{array}$ \\
\hline Communication & $\begin{array}{ll}\text { I } & \text { Patient and family } \\
2 & \text { Practice staff } \\
3 & \text { Peers } \\
4 & \text { Other professionals }\end{array}$ \\
\hline Professionalism & $\begin{array}{l}\text { I Ethics } \\
2 \text { Personal professionalism } \\
3 \text { Professionalism towards patients } \\
4 \text { Professionalism towards staff and peers }\end{array}$ \\
\hline Managerial & $\begin{array}{l}\text { I Personal and practice management } \\
2 \text { Financial management } \\
3 \text { Legislataive management }\end{array}$ \\
\hline
\end{tabular}

trainers and currently any trainer who has serious doubts about the competence of a trainee is ethically obliged to disclose their concerns to a higher authority. ${ }^{12}$ Assessment would mean only that the quality of the training given and the competence of the trainees is monitored and enforced. In addition the regulation of postgraduate training, particularly with regard to trainees who lack competence, sought by many trainers would then be provided.

Clearly such a system will demand that additional support be provided for trainers and trainees alike. A comprehensive program of training for the trainers must complement any system that is introduced. Trainers will need support and guidance in the delivery of training and in the parts of the assessment system in which they may be involved directly. Similarly, trainees experiencing problems in specific areas of training should be supported and if necessary additional instruction at an appropriate stage in the course so that steps are taken to rectify problems.

\section{The project's progress}

The project began in April 1999 and the first stage in the design of an assessment system is the clear identification of the desired outcomes of training, i.e. exactly what is to be assessed. In the case of a competency-based system this is the identification of competencies.

A review of published dental competency systems revealed a number of programs in practice worldwide. The vast majority of these systems (including those in Europe) relate to undergraduate curricula ${ }^{13-15}$ although investigations into the issue of competence for postgraduate education have begun. ${ }^{15-17}$ Perhaps one of the clearest messages obtained from the literature was the almost universal acceptance of the terminology used to describe the hierarchy of competencies within a particular program. Starting from the most general term, a domain describes a broad area of professional activities and responsibilities. Within each domain there are major competencies which relate to distinct areas of professional 
Table 2 Supporting competencies whin the major competency patient and family (communication domain)

I The trainee can demonstrate to an appropriate standard the ability to increase the awareness and understanding of patients (from all age groups or situations) during the explanation of treatment options and procedures, through the use of effective verbal communication skills.

2 The trainee can demonstrate to an appropriate standard the ability to inspire confidence in patients (from all age groups or situations) through the use of effective interpersonal and communication skills.

3 The trainee provides up-to-date preventive education to all patients in a manner that inspires motivation for change. The trainee is able to explain in appropriate detail the behavioural techniques which drive motivation in individuals from different age groups and situations, and the psychological evidence supporting these procedures. The trainee is able to describe in appropriate detail the social factors which may affect the implementation of preventive education, and ways in which these may be overcome.

4 The trainee can demonstrate the ability to select and compose the correct styles of written comunication that are appropriate for patient and/or guardian in different clinical situations.

5 The trainee can demonstrate to an appropriate standard the ability to refer patients from the different age groups or situations for specialist treatment in a sensitive manner which causes the least anxiety possible.

6 The trainee can demonstrate to an appropriate standard the effective management of difficult or anxious patients through the use of suitable interpersonal and behavioural skills. The trainee can explain in appropriate detail the logic behind these methods.

7 The trainee can demonstrate to an appropriate standard the ability to communicate effectively with relatives, whilst not undermining the respect shown towards the patients. considered that there are four main sectors in which the dentist must communicate with patients and their families/guardians, with practice staff, with peers and with other professionals such as medical staff, laboratory technicians etc. The detail of how this communication needs to be performed, such as the interpersonal skills necessary to inspire confidence, communication of knowledge or in debate with peers, is included in the individual supporting competency statements (Table 2).

A total of 12 major competencies have been identified in the clinical domain (Table 1 ). As the focus of all health professions moves towards recognising the primacy of desired patient outcomes over the needs of the provider, an attempt has been made to develop major competencies which reflect this trend and move away from the departmentalisation that is traditionally observed in dentistry. The concept that assessment drives learning is well known, and the adoption of a patient centred approach both for the development of a competency document and an assessment system, is intended to promote the importance of patient care to new dentists.

The development of competency statements has become something of an artform in recent years, to the point that a manual specifically for this purpose has been published. ${ }^{18}$ Recommendations for the format of competency statements comprise a three part structure that includes (a) a verb, (b) direct object and (c) qualifying conditions, special circumstances, limitations and explicit outcomes. Chambers et $\mathrm{al}^{18}$ also recognise that 'competency statements will only be effective if they are tailored to individual circumstances.' The originality of this project, in its involvement with the competency-based assessment of postgraduate training rather than curriculum development, has dictated subtle changes to this format. Firstly, if competence is to be assessed then the active performance of the task must be requested in the statement, i.e. 'the trainee can demonstrate...' or 'the trainee can describe...' Also, the fact that a particular level of ability will be expected from the trainee must be declared by means of phrases such as 'to an 


\section{EDUCATION competency}

appropriate standard...' or 'in appropriate detail...' Although this additional detail lengthens each statement somewhat, the result should be competencies which are robust and open to evaluation.

The recent completion of the competency document represents the first major milestone in this project. 'Completion' means that the document identifies our objectives for the assessment of this period of dental training but the definition of competencies is a never-ending process, a fact reiterated by establishments who have implemented such changes in the past. ${ }^{19,20}$ Revision of the competency document will be on-going, as dentistry changes over time and as feedback provided by the dental community informs further development.

The second and undoubtedly the most challenging stage of the project - the investigation into assessment is now underway. The assessment methods used must be valid, reliable and feasible and must be applicable to both the undergraduate and early postgraduate phases of dental education. Clearly the assessment of each competency on an individual basis would be impractical, and the competency document is not meant to be used in such a way. It is meant to be used as a reference point to direct trainers, drive training and act as a comprehensive guide for assessment. Ulti- mately, assessment of the application of clinical and generic skills, judgement and self-assessment to different situations, in association with a commitment to lifelong learning and a professional approach, will be a vital indication of all-round competence. The possession of such traits will indicate whether a dentist will have achieved a sufficient degree of competence at a landmark point in his/her career, and whether he/she can be expected to provide and maintain the highest standards of patient care in the future.

This work is being funded by the Scottish Council for Postgraduate Medical and Dental Education (SCPMDE).

The authors would like to thank the Steering Group involved in this project for their help and support.

1 Baldwin P J, Dodd M, and Rennie J S. Postgraduate dental education and the 'new' graduate. Br Dent J 1998; 185: 591-594.

2 Being There. Editorial Comment The Dentist May 1999; 6.

3 Allen W R. Mandatory Vocational training for the General Dental Services. Br Dent J 1993; 175: 188.

4 Murray J J. The Continuum of Dental Education — one year on. Br Dent J 1996; 180: 149-151.

5 Department of Health White Paper 'Primary Care: Delivering the Future' 1996.

6 Plowman L and Musselbrook K. An Evaluation of General Professional Training for Dentistry in Scotland. Br Dent J 2000: In Press

7 Musselbrook K, Plowman L, and Devine M. A Bridge to the Future: An Evaluation of General Professional Training for Dentistry in Scotland.
Scottish Council for Postgraduate Medical and Dental Education 1999.

8 Musselbrook K, Plowman L, and Devine M Evaluation of General Professional Training West Midlands. Scottish Council for Research in Education 1999.

9 Cabot L B, Radford D R. Are graduates as good as they used to be? Br Dent J 1999; 186: 318-9.

10 Firestone H, Mackie I C. Graduate Training Expectations. Br Dent J 1999; 187: 4.

11 Batchelor P, Albert D. Issues Concerning the Development of a Competency-based Assessment System for Dentistry. Br Dent J 1998; 185, 141-144.

12 General Dental Council. Maintaining Standards. 1997.

13 Advisory Committee on the Training of Dental Practitioners. Competences Required for the Practice of Dentistry in the European Union. 1993.

14 Advisory Committee on the Training of Dental Practitioners. Core Knowledge and Understanding. 1997.

15 Mossey P, Stirrups D R. Clinical Competencies in Dentistry - Exploring the Issues. 1997.

16 Advisory Committee on the Training of Dental Practitioners. Post Graduate Competencies Pre-Specialist Training. 1999.

17 Advisory Committee on the Training of Dental Practitioners. Postgraduate Competence. 1999.

18 Chambers D W, Gerrow, J D. Manual for Developing and Formatting Competency Statements. J Dent Educ 1994; 58: 361-366.

19 McCann A L, Babler W J, Cohen P A. Lessons Learned from the competency Based Curriculum Initiative at Baylor College of Dentistry. J Dent Educ 1998; 62, 197-207.

20 Glassman P, Chambers D W. Developing Competency Systems: A Never-Ending Story. J Dent Educ 1998; 62: 173-182. 